\title{
CUIDADO DE ENFERMAGEM A PESSOAS COM HIPERTENSÃO FUNDAMENTADO NA TEORIA DE PARSE
}

\author{
Nursing care to people with hypertension based on Parse's theory \\ Atención de enfermería a personas con hipertensión basada en la teoría de Parse
}

Fabíola Vládia Freire da Silva ${ }^{1}$

Lúcia de Fátima da Silva²

Maria Vilani Cavalcante Guedes ${ }^{3}$

Thereza Maria Magalhães Moreira ${ }^{4}$

Ana Cleide Silva Rabelo 5

Keila Maria de Azevedo Ponte ${ }^{6}$

\section{RESUMO}

Este estudo propõe o cuidado de enfermagem, baseado nos princípios de Parse, a pessoas com hipertensão consultadas na Estratégia Saúde da Família. Estudo descritivo, de cunho qualitativo, realizado de março a maio de 2011, com quatorze enfermeiros no município de Itapajé-Ceará. Para coleta das informações utilizou-se a entrevista semiestruturada e, para análise, o discurso dos sujeitos. Emergiram três categorias baseadas nos princípios de Parse: Multidimensão dos significados - o enfermeiro conduz ao relato dos significados; Sincronização de ritmos - o enfermeiro ajuda a identificar harmonia e desarmonia; Mobilização da transcendência - o enfermeiro guia o plano de mudanças. Notou-se aproximação dos discursos ao teorizado por Parse quando citaram buscar um cuidado humanizado, com a participação da família, valorização da autonomia, utilização da educação em saúde, com orientações individuais. Percebeu-se a viabilidade na implementação do cuidado de enfermagem fundamentado na Teoria de Parse a pessoas com hipertensão.

Palavras-chave: Teoria de enfermagem. Cuidados de enfermagem. Hipertensão.

\begin{abstract}
This study proposes the nursing care, based on Parse's principles, to people with hypertension assisted in the Family Health Strategy. Descriptive study of qualitative approach carried out from March to May 2011, with fourteen nurses in the municipality of Itapajé-CE, Brazil. For data collection we used semi-structured interview and for analysis we used the subjects' discourse. Three categories emerged based on Parse's principles: The multidimensional meanings - the nurse leads to the meanings report; Synchronization of rhythms - the nurse helps identifying harmony and disharmony; Mobilization of transcendence - the nurse guides the plan of changes. It was verified the approach of discourses to Parse's theory when mentioned seeking a humanized care, with family participation, valuing autonomy, use of health education, with individual orientations. It was noticed the viability in the implementation of nursing care based on Parse's theory to people with hypertension.
\end{abstract}

Keywords: Nursing Theory. Nursing Care. Hypertension.

\section{Resumen}

Este estudio propone la atención de enfermería, basada en los principios de Parse, para personas con hipertensión en la Estrategia de Salud Familiar. Estudio descriptivo, cualitativo, realizado de marzo a mayo/ 2011, con catorce enfermeros en Itapajé, Ceará. Para la recolección de las informaciones, se utilizóla entrevista semiestructurada y para análisis, el discurso de los sujetos. Emergieron tres categorías: Multidimensiones de los significados - el enfermero conduce al relato de los significados; Sincronización de los ritmos - el enfermero ayuda aidentificar armoníay desarmonía; Movilización de la trascendencia-el enfermero guía el plan de cambios. Se observó semejanzas entre el enfoque de los discursosy la Teoría de Parse, cuando citaron la búsqueda de atención humanizada, con participación de la familia, valoración de la autonomía, uso de la educación en salud, con orientaciones individuales. Se observó la viabilidad en la ejecución de la atención de enfermería basada en la Teoría de Parse a personas con hipertensión.

Palabras clave: Teoría de Enfermería. Atención de Enfermería. Hipertensión

\footnotetext{
'Enfermeira. Aluna do Mestrado do Programa de Pós-Graduação Cuidados Clínicos em Enfermagem e Saúde (PPCCLIS) da Universidade Estadual do Ceará (UECE). Bolsista da Coordenação de Aperfeiçoamento de Pessoal de Nivel Superior (CAPES). Integrante do Grupo de Pesquisa Enfermagem, Educação, Saúde e Sociedade (GRUPEESS), da UECE. Fortaleza-CE. Brasil. E-mail: fabiolafreire@yahoo.com.br ;'Enfermeira. Doutora em Enfermagem. Docente do Curso de Graduação em Enfermagem e do PPCCLIS da UECE. Enfermeira do Hospital de Messejana Dr. Carlos Alberto Studart Gomes. Pesquisadora do GRUPEESS. Fortaleza-CE. Brasil. E-mail: luciadefatima.ce@terra.com.br ; ${ }^{3}$ Enfermeira. Doutora em Enfermagem. Docente do Curso de Graduação em Enfermagem e do PPCCLIS. Pesquisadora do GRUPEESS. Fortaleza-CE. Brasil. E-mail: vilani.guedes@globo.com ; ${ }^{4}$ Enfermeira. Doutora em Enfermagem. Docente do Curso de Graduação em Enfermagem e do PPCCLIS da UECE. Fortaleza-CE. Brasil. E-mail: thereza.moreira@uece.br ; ${ }^{5}$ Enfermeira. Aluna do Mestrado do PPCCLIS. Integrante do GRUPEESS. Fortaleza-Ceará, Brasil. Fortaleza-CE. Brasil. E-mail: anaceidesr@hotmail.com; ${ }^{6}$ Enfermeira. Aluna do Doutorado do PPCCLIS. Mestre em Cuidados Clínicos. Integrante do GRUPEESS. Fortaleza-CE. Brasil. E-mail: keilinhaponte@hotmail.com
} 


\section{Cuidado de enfermagem fundamentado em Parse}

\section{INTRODUÇÃO}

Objetivou-se destacar o cuidado proporcionado pelo enfermeiro às pessoas com hipertensão arterial sistêmica (HAS), buscando identificar conceitos da Teoria de Enfermagem de Rosemarie Rizzo Parse, no modo como o cuidado a esta clientela é praticado no contexto da Estratégia Saúde da Família (ESF) ${ }^{1}$.

A abordagem de estudos que contemplem o cuidado de enfermagem baseados em teorias vem dando sustentabilidade à profissão por fortalecer a prática; com base nisso, quando se trata de cuidar no adoecimento crônico, neste caso de pessoas com HAS, tornam-se relevantes diversos aspectos relacionados a estas doenças.

Se este cuidado envolve um longo período de tempo e a não perspectiva de cura, a exemplo de pessoas com HAS, exige-se do enfermeiro mais empenho e paciência, porquanto o cuidador e a pessoa cuidada devem estabelecer uma relação de mútua confiança e empenho para o êxito do tratamento.

Cabe aos profissionais de saúde orientar e estimular permanentemente a pessoa com HAS a modificar os hábitos nocivos e auxiliar no controle dos níveis pressóricos. Nesta perspectiva, requer-se o conhecimento das variáveis que influenciam no tratamento, com vistas a facilitar o dimensionamento da prática do cuidado de enfermagem para cada necessidade ${ }^{2}$.

Para isso, a interação entre a pessoa que cuida e o ser cuidado deve ocorrer de forma efetiva no intuito de possibilitar a adesão ao tratamento. 0 enfermeiro deve, portanto, considerar que o cuidado por ele dispensado ao paciente não é uma imposição de conhecimentos, mas sim uma troca de saberes e de confiança.

No contexto da hipertensão arterial, o cuidar deve ter como princípio básico assistir o cliente e a família e auxiliá-los no desenvolvimento de habilidades e atitudes que proporcionem um autocuidado efetivo deste problema crônico de saúde. Tal tipo de cuidado envolve, além do paciente, a família e a própria comunidade na qual ele se insere, incluindo ações que ultrapassam o tratamento de doenças, como a promoção, prevenção e reabilitação em saúde.

A filosofia do cuidado às pessoas com HAS, no contexto da ESF, valoriza a utilização da autonomia do paciente e o auxílio da família no processo de cuidar. Como parte deste processo, além de consultas individuais mensais e de grupos de pessoas com hipertensão, onde estes são orientados quanto às medidas de controle da doença, há ainda a visita semanal dos agentes comunitários de saúde, aptos a esclarecer dúvidas e trazer incentivo à continuidade do tratamento, tanto ao indivíduo com hipertensão como à família, sendo esta colaboradora do processo.

Contudo, para poder a enfermagem atuar eficientemente, é preciso desenvolver seu trabalho com suporte no método científico. Portanto, a investigação científica deve ser guiada pela teoria, que orienta a prática de enfermagem, descrevendo, explicando ou prevendo fenômenos. Para a prática cuidativa da enfermagem, é necessário fazer um planejamento e listar objetivos a serem cumpridos. Isso se verifica por meio da Sistematização da Assistência de Enfermagem (SAE) e da utilização de referenciais teóricos, os quais buscam dar fundamentação e cunho científico ao cuidado prestado.

Entre os referenciais teóricos, adotou-se, neste estudo, a Teoria "Human Becoming", de Rosemarie Rizzo Parse ${ }^{1}$. Esta teorista considera o ser humano um ser único e possuidor de livre arbítrio. É ele quem comanda a si mesmo e tem a liberdade em suas decisões. 0 enfermeiro aparece como mediador e colaborador no processo de recuperação ou manutenção de um tratamento.

Embora ainda pouco difundida no Brasil, a Teoria de Parse traz em seu teor as tendências atuais de valorização da pessoa como agente da sua saúde e responsável por ela, enfim, o respeito incondicional ao homem como ser humano e à sua existência ${ }^{3 .}$

Segundo esta teoria, a enfermagem é considerada ciência humana cujo foco central é o ser humano. Como afirma Parse, a essência da enfermagem é o relacionamento enfermeiro-pessoa, e sua meta principal é a qualidade de vida sob a perspectiva da pessoa. Ao aplicar a Teoria de Parse, 0 enfermeiro deve respeitar a visão de qualidade de vida de cada um, que difere de pessoa para outra, e não tentar mudar essa visão para ser consistente com sua própria perspectiva ${ }^{3}$.

Os princípios descritos pela teorista fazem referência ao protagonismo do sujeito em seu processo de tratamento, 0 qual deve ser estimulado pelo profissional que 0 atende. No primeiro princípio, o indivíduo é responsável pela construção e escolha dos seus significados, usando-os no seu processo de saúde. No segundo, cada indivíduo reage e interage com os estímulos externos de forma diferente. No terceiro, as mudanças e a valorização de novas possibilidades são incentivadas, levando-se em conta a individualidade da pessoa, suas relações com os outros e com o meio'.

Um exemplo da utilização desta teoria na prática de enfermeiros foi citado em um estudo de caso clínico, realizado durante entrevista pré-operatória. Nela a enfermeira utilizouse da teoria para guiar seu cuidado, tendo obtido resultados bastante positivos, ao passo que o paciente, ao relatar seus significados e sentimentos quanto ao procedimento cirúrgico ao qual iria se submeter, pôde se sentir protagonista do seu cuidado; assim, o agir da enfermeira passou de um simples preenchimento de um questionário pré-estabelecido, para um cuidar individualizado e humanizado ${ }^{4}$.

Exemplo semelhante ocorreu em um estudo realizado no Japão, com um paciente com complicações pós-cirúrgicas. A teoria foi utilizada no cuidado a este paciente e a sua esposa, e pôde-se perceber que a relação da enfermeira com o paciente e seu familiar ocorreu de forma mais efetiva, com um vínculo de confiança necessário a um cuidar de qualidade, além de 
possibilitar ao paciente participar nas decisões quanto à sua saúde, proporcionando-lhe retorno de sua motivação e qualidade de vida ${ }^{5}$.

Conforme observado, o conteúdo desta teoria mostrase condizente com o contexto do cuidado prestado pelo enfermeiro, seja no ambiente hospitalar ou na ESF, pois tanto a estratégia como os princípios da teoria apontam para a busca da valoração do indivíduo e sua inclusão como agente promotor da própria saúde.

Assim, diante do contexto da abordagem da HAS pela ESF, que continua a se configurar relevante problema de saúde pública, das responsabilidades do enfermeiro no tocante ao cuidado a esta população e da possibilidade de utilizar teorias de enfermagem na prática assistencial como ferramenta de valoração da prática profissional, questiona-se: Há, no discurso dos enfermeiros da ESF, alguma aproximação com os princípios propostos por Rosemarie Parse em sua teoria?

Deste modo, este estudo se volta para a investigação da prática cuidativa de um grupo de enfermeiros que prestam cuidados às pessoas com HAS atendidas pela ESF, buscando identificar os princípios propostos por Rosemarie Parse nesta prática, analisando-a conforme o descrito na teoria, considerando que os conceitos teorizados por Parse são condizentes com a atuação dos enfermeiros proposta pela ESF.

\section{REFERÊNCIAL TEÓRICO METODOLÓGICO}

\section{Referencial teórico}

A teoria de Rosemarie Rizzo Parse busca a valorização do homem e de sua singularidade, contribuindo, assim, no seu processo de saúde, pois este se torna o protagonista de seu tratamento, tornando mais fácil sua adequação à nova condição advinda com um processo de adoecimento. A família também aparece como participativa e colaboradora. 0 enfermeiro atua como mediador e esclarecedor do significado do adoecimento e auxilia o paciente na modificação de seu estilo de vida, ressaltando que o paciente é quem está a frente dessas transformações ${ }^{1}$. Os princípios da teoria de Parse são três, como segue:

$1^{\circ}$ PRINCIPIO: Estruturar o significado multidimensionalmente é cooperar na criação da realidade por meio da expressão de valores e imagens. Este princípio postula que o ser humano encontra o significado para a situação em que se está quando imagina essa situação em outras dimensões, fazendo a escolha do significado com base nos seus valores pessoais. Ao expressar as imagens valorizadas, consegue compreender e definir o que aquela experiência que está sendo vivida significa para ele. Desta forma, surge uma nova realidade, criando novos padrões de vida. Multidimensionalmente refere-se aos vários níveis do universo que o homem experimenta ao mesmo tempo'.

$2^{\circ}$ PRINCÍPIO: Cooperar na criação de padrões rítmicos de relações é viver a unidade paradoxal de revelar-ocultar, capacitar-limitar ao mesmo tempo que unir-separar. 0 princípio explica que, ao viver os paradoxos, a pessoa revela alguns aspectos do seu "eu" e ao mesmo tempo oculta outros. Nunca se sabe tudo que há para saber sobre si, o ser humano vai se revelando no processo de transformar-se. A pessoa não pode ter todas as possibilidades ao mesmo tempo. Em cada situação o ser humano encontra-se capacitado para mover-se em uma direção e limitado para outra. Ao mover-se em direção a uma escolha, separa-se da outra possibilidade. Isso resulta em integração ao pensamento, torna-o mais complexo e o direciona a buscar novas opções'.

$3^{\circ}$ PRINCÍPIO: Cotranscender as possibilidades é procurar maneiras únicas de iniciar o processo de transformação. Cotranscender, para Parse, significa moverse para outras dimensões com sonhos e esperanças cultivados, criando novas formas de perceber o que já é conhecido. Quando a pessoa cotranscende cria forças para originar novas formas de viver, transformando, assim, seus padrões de vida. Transformar é viver novas possibilidades imaginadas. A mudança é um processo contínuo do ser humano em relação com o meio ambiente, movendo-se do que é para o que ainda não é .

\section{Método}

Trata-se de um estudo descritivo com abordagem qualitativa, com utilização do referencial teórico de Parse na sua construção. Como sujeitos do estudo, participaram quatorze enfermeiros que cuidam de pessoas com HAS acompanhadas pela ESF do município de Itapajé-CE. Estas foram convidadas a participar do estudo mediante convite formal na Secretaria de Saúde do Município. Utilizou-se como critério de inclusão a atuação dos enfermeiros no cuidado às pessoas com hipertensão na ESF, e como critério de exclusão, o gozo desses profissionais, naquele momento, de férias e/ou licença de qualquer natureza.

A coleta de dados ocorreu no período de março a maio de 2011, por meio de entrevista semiestruturada, realizada individualmente, tendo como questão norteadora a descrição da prática cuidativa da(o) enfermeira(0) a pessoas com HAS no âmbito da ESF. Os discursos foram gravados, e a transcrição foi fiel e ocorreu imediatamente após cada entrevista, seguindo-se a análise. Também foi utilizado um formulário para caracterização dos sujeitos da pesquisa, do qual constaram variáveis sociodemográficas, além de dados sobre a formação profissional dos entrevistados. Estes foram aplicados após esclarecimentos sobre os objetivos da pesquisa e assinatura do Termo de Compromisso Livre e Esclarecido.

Para apreciação dos dados, adotou-se a Análise do Discurso, isto é, uma prática em um campo da linguística e da comunicação especializada em analisar construções ideológicas presentes em um texto ${ }^{6}$.

Nesse sentido, tentou-se identificar figurações nas falas dos enfermeiros que possibilitassem a apreensão de temas relacionados com os princípios de multidimensão dos 
significados, sincronização de ritmos e mobilização da transcendência, propostos por Rosemarie Rizzo Parse em sua teoria. Os dados coletados por meio do formulário foram organizados de modo a apresentar o perfil sociodemográfico e profissional dos enfermeiros estudados, identificados com a letra E, de entrevistado, seguida de um numeral arábico.

Conforme determinado, observaram-se os preceitos ético-legais da Resolução 196/1996, do Conselho Nacional de Saúde, e obteve-se aprovação do Comitê de Ética em Pesquisa da Universidade Estadual do Ceará com parecer número 10724498-5.

\section{RESULTADOS E DISCUSSÃO}

A seguir, apresentam-se o perfil sociodemográfico e profissional dos participantes e a discussão obtida da confrontação do discurso dos enfermeiros da ESF com os princípios de Parse.

\section{Perfil sociodemográfico e profissional dos participantes}

Os sujeitos do estudo foram quatorze enfermeiros, com predominância de mulheres, no total de onze. Inferiu-se que tal fato se evidencia ao perfil ainda feminino da profissão. Acerca da faixa etária, os participantes tinham entre 23 e 55 anos, não havendo predomínio de um determinado intervalo de idade.

No relacionado à crença religiosa, sete participantes referiram ser adeptos do catolicismo e sete afirmaram ser evangélicos. Cabe apontar: tais crenças interferem no pensamento e no modo de agir do profissional, mesmo subjetivamente. Os ensinamentos de amor e fraternidade transformam não somente a sociedade, mas também 0 desenvolvimento da Enfermagem, marcando, ideologicamente, a prática de cuidar do outro e modelando comportamentos que atendessem a esses ensinamentos? ${ }^{7}$.

No inerente à renda dos participantes, dois recebiam cerca de quatro salários mínimos mensalmente, e os demais, três salários mínimos. Essa pequena disparidade se explica por haver uma complementaridade da renda, advinda de outro emprego, por parte dos participantes que a declararam maior.

Segundo consta em estudo, a remuneração financeira digna constitui-se um fator significativo na determinação da motivação para o trabalho e satisfação com a qualidade de vida ${ }^{8}$.

Quanto ao perfil profissional dos participantes, de acordo com a instituição de ensino, oito cursaram faculdades públicas e seis, instituições particulares. 0 tempo de duração do curso de graduação variou entre três anos e meio até sete anos. Pontuando o ano de graduação, houve grande diversidade de datas. 0 participante que concluiu o curso há mais tempo 0 fez em 1984 e o mais recente, em 2010.

Tal dado sugere uma multiplicidade de formações acadêmicas, principalmente em face das diversas mudanças nas diretrizes para a formação dos enfermeiros com consequentes alterações nas grades curriculares do curso. Cabe destacar, também, que as mudanças advindas da implantação do Sistema Único de Saúde (SUS) tornaram fundamental a adequação dos cursos de graduação à nova forma de cuidar por este defendida.

No tocante à formação complementar, dez participantes mencionaram especializações. Quando questionados a respeito da realização de cursos de atualização profissional, dez afirmaram fazer cursos na área da ESF. Destes, sete disseram o fazer anualmente e três, semestralmente. Também cinco sujeitos realizaram cursos nos quais se abordaram a SAE e as Teorias de Enfermagem e nove, cursos sobre o cuidado à pessoa hipertensa.

$\mathrm{Na}$ atual sociedade, a competência profissional é cobrada de modo bastante ostensivo. Entretanto, há de se superar a busca exclusiva pela titulação universitária e privilegiar a formação de um profissional com horizonte mais amplo, com valores éticos e com capacidade de aprendizagem constante 9 .

Sob o prisma da atuação profissional, seis profissionais estão na ESF há cerca dez anos ( \pm 3 anos), enquanto os demais estão há menos de três anos. Contudo, a maioria está na ESF do município há menos de três anos. Quanto às experiências anteriores, dez participantes disseram ter trabalhado em outras áreas de atuação da enfermagem, mas quatro afirmaram ser a ESF sua única experiência.

No concernente à área de atuação, cinco participantes trabalham na zona rural, cinco na zona urbana e quatro em ambas. Sobre o vínculo empregatício, nove participantes têm contratos temporários e cinco são concursados.

Apresentam-se a seguir as categorias surgidas dos discursos. Estes foram organizados aproximando-os das categorias teóricas de análise compostas pelos princípios de Parse $^{1}$, quais sejam: Multidimensão dos significados - 0 enfermeiro conduz ao relato dos significados; Sincronização de ritmos - o enfermeiro ajuda a identificar harmonia e desarmonia; Mobilização da transcendência - o enfermeiro guia o plano de mudanças.

\section{Multidimensão dos significados: o enfermeiro conduz ao relato de significados}

Segundo este primeiro princípio da Teoria de Parse, cada indivíduo visualiza o mundo de uma forma diferente, e isso depende do ambiente onde ele está inserido, além dos determinantes que o cercam".

Do discurso dos enfermeiros emergiu a definição de como se dá o cuidado a pessoa com hipertensão na ESF:

A estratégia do cuidado à pessoa hipertensa não se resume só à doença. A gente vê também o lado emocional, o lado físico, e a expressão, como ele está diante do problema dele (E1). 
0 atendimento aos hipertensos é um atendimento humanizado, voltado pra situação em si, deles (E6).

Nessas falas evidencia-se o conceituado por Parse, com a ideia de um cuidado mais ampliado, quando citam que este não se resume só à doença e que deve ser humanizado.

Viabilizar a humanização nos serviços de saúde pressupõe transcender a usual produção de saúde voltada apenas para a cura plena, direcionando a operacionalização de práticas focadas na satisfação do usuário por meio de um atendimento de qualidade, o acolhimento integral, permitindo a "escuta" das dificuldades dos usuários e sua resolubilidade, ou seja, praticando o cuidado integral ${ }^{10}$.

Considerando o exposto, e conforme se notou, este cuidado de forma humanizada ainda precisa ser aperfeiçoado na prática. Na fala de E5 é exemplificada essa carência no cuidado:

O cuidado com o idoso [hipertenso], eu acho que deixa muito a desejar. A gente, às vezes, anula um pouco o idoso. Ele vem para contar, para falare, tem muito idoso, e às vezes, a gente está um pouco impaciente [...] e, na verdade, não tem como a gente fazer tudo, solucionar todos os problemas e as queixas, né?! (E5).

Essa dificuldade de ouvir as demandas dos pacientes e de tratá-los como sujeitos singulares, com desejos, crenças e medos, tem se constituído como causa de inúmeros fracassos na relação entre os trabalhadores de saúde e a população por eles assistida. Isso também ocorre porque o indivíduo, ao ser rotulado por sua morbidade, perde sua individualidade, e a humanização do cuidado se torna ainda mais difícil.

Conforme Parse, em sua teoria, o ser humano é mais do que a soma das partes, ele é unitário, e isso não significa apenas constituir-se como uma combinação de entidades ou peças, mas reflete uma formação surgida de um contexto singular ${ }^{11}$.

Assim pode-se citar o acolhimento como instrumento importante para a prática de um cuidado individualizado e integral, pois consiste no primeiro contato do enfermeiro com o paciente, permitindo conhecê-lo, propiciando, assim, o início de um vínculo. Nos discursos dos enfermeiros houve referência ao momento do acolhimento e da sua importância para 0 relacionamento terapêutico:

Quando chega um paciente hipertenso é feito o acolhimento (E9).

Eu procuro fazer a minha parte no sentido de acolhêlos, tratá-los de uma forma carinhosa para que eles não fiquem constrangidos, se sintam bem à vontade (E1).
É preciso, pois, valer-se desse momento para principiar uma relação de confiança. Perdê-lo torna mais difícil o acompanhamento dos pacientes por parte dos enfermeiros, além de subvalorizar essa relação como instrumento terapêutico.

Se tiver a medicação na farmácia, ele não quer nem falar com você. Só é para ir buscar e tchau; medir a pressão, olhar a glicemia e vai embora (E5).

Consoante se nota, inexiste demonstração de confiança entre o paciente e o profissional, porquanto 0 paciente não mantém uma relação terapêutica com o enfermeiro. Desta forma, desconsidera a importância desta, diferentemente do teorizado por Parse, para quem conhecer o indivíduo e os significados que o envolvem são o primeiro passo para o cuidado'.

É válido ressaltar: se não se verificar um vínculo inicial efetivo, é comum ocorrer evasão e déficit da adesão ao tratamento. Como referido pelos enfermeiros, a evasão pode ser fortalecida pelo analfabetismo, o qual está relacionado ao contexto em que o paciente está inserido. Este, como postula Parse, deve ser considerado um fator repleto de significação. 0 analfabetismo aqui se mostra como uma "venda", um dificultador para a compreensão do adoecimento e do seu tratamento. Nesta ótica, um paciente que não sabe ler deve ser visto com maior atenção. Sendo assim, observase o significado deste fator para os sujeitos do estudo:

Tem muitos pacientes que não sabem ler, e a gente tem que ter um cuidado mais apurado (E2). A gente tem que ter o cuidado aqui com a forma como o hipertenso está tomando a medicação. Muitos tomando errado, muitos não sabem ler (E4).

Como se evidencia, o conhecimento do contexto socioeconômico e cultural da pessoa com HAS torna-se imprescindível para que o enfermeiro, ao planejar o cuidado, modele-o de acordo com as necessidades e possibilidades do cliente assistido, tornando, assim, mais palpável a obtenção de resultados efetivos e de continuidade do tratamento. Entretanto, o não seguimento do plano terapêutico é bastante comum aos pacientes com hipertensão:

Eles têm uma certa resistência, no sentido de que eles acham assim: eu não estou ficando bom, então eu vou parar a medicação, porque não está dando resultado. Eles não têm a ideia fixa ainda de que a medicação é um controle (E1). 
Como observado, muitas pessoas com HAS passam por um processo de não aceitação da sua situação de morbidade. Já que o paciente não aceita estar doente, consequentemente, não acha necessário se cuidar. Nos discursos a seguir, confirmam-se estas palavras:

Quando eles veem que a pressão está controlada, querem logo parar de tomar a medicação (E14).

E a gente aborda muito a questão da dieta, também, que é uma coisa que eles são muito dificeis. Eles querem se encher de remédios, mas não querem tirar o sal, a gordura, não querem evitar (E5).

Na Teoria de Parse o ser humano é visto como um ser aberto, com liberdade para escolher significados a partir dos seus valores pessoais ${ }^{1}$. Contudo, cabe ao enfermeiro esclarecer o significado do adoecimento, o qual requer do paciente uma mudança de atitudes, respeitando-se, porém, sua liberdade de escolha e sua singularidade.

Segundo se acredita, quando o paciente com hipertensão compreende o significado pessoal para a situação vivenciada, centrada em valores prioritários, cria formas de vivenciar esta situação no meio ambiente onde vive, e busca dentro das possibilidades melhorar sua qualidade de vida, responsabilizando-se pelas suas decisões ${ }^{1}$. Isso nos remete ao segundo princípio de Parse abordado a seguir.

\section{Sincronização de ritmos: o enfermeiro ajuda a identificar harmonia e desarmonia}

No segundo princípio de Parse - sincronização de ritmos - consta o processo de tratar do fluxo da cadência interhumana (a mudança, o movimento rotativo e o impulso das relações humanas)'.

Ao invés de acalmar ou tentar equilibrar esses ritmos, o enfermeiro segue os ritmos fixados pelo paciente e o conduz, mediante discussão, no sentido de reconhecer as possibilidades existentes no próprio contexto por ele vivido, incentivando a autonomia. No discurso dos enfermeiros este incentivo é perceptível:

A gente tem que ver se ele está se cuidando, né? Porque a gente tem a preocupação de estar capacitando o paciente para ele se cuidar (E1).

Todavia, muitas vezes, o paciente com hipertensão não tem a real noção do quanto é importante seguir corretamente um esquema terapêutico. Neste contexto, a autonomia nem sempre ajudará no seu tratamento. Por isso, também é importante a presença de um cuidador, como é possível ver nas falas dos entrevistados:
Muitos tomam a medicação errado, muitos não sabem ler, muitos têm um cuidador, então a gente conversa com o cuidador, conversa com o paciente, faz esquemas (E4).

Ressalta-se que a equipe de saúde, em especial o enfermeiro, não perde a responsabilidade pelo paciente. Além de contribuir com a distribuição de medicações e aferição da pressão arterial, cabe-lhe orientar quanto às medidas necessárias para o controle da hipertensão arterial, como mostram as falas de E1 e E8:

E, assim, a gente fica tentando sempre orientar (E1).

Converso com eles e oriento [...] (E8).

De acordo com estudo, o enfermeiro é um colaborador no processo de cuidar do paciente 1 . Um exemplo desta colaboração são as orientações dadas no tocante à medicação, à prática de exercícios físicos e à dieta, como descrito a seguir:

A gente questiona o uso da medicação, se eles fazem o uso da medicação. Eles dizem que, quando não estão bem, fazem. Tem dias que faz (uso dos anti-hipertensivos), tem dias que não faz. Muitas vezes o cuidador também não colabora[...] (E5).

E a questão da qualidade de vida [...] a gente orienta, claro, principalmente a questão da alimentação [...] (E12).

Segundo Parse, a enfermeira deve focar sua atenção na dinâmica do indivíduo/família, no seu fluxo de vida, deve levá-los a reconhecer a harmonia presente na sua vida. Deve se entregar ao convivio, mas sem envolver o próprio eu, aproximando-se dos valores do indivíduo e apagando-se $\mathrm{s}^{12}$.

Contudo, a ideia proposta por Parse ainda se mostra utópica na prática assistencial dos enfermeiros, até porque 0 modelo de saúde vigente direciona a práticas muito padronizadas, nas quais existe sempre uma solução "pré-fixada" para determinado problema.

Um desses problemas é a valorização de fármacos como "único" tratamento ao hipertenso. Se a medicação não é o foco, há visível dificuldade quanto ao seguimento das orientações dadas pelo profissional de saúde, o que compromete muito o êxito do processo terapêutico. A fala a seguir exemplifica tal dificuldade:

A gente tem dificuldade na questão da alimentação, por mais que a gente oriente (E7). 
E aí, para mudar uma cultura, já é você invadir a privacidade do paciente (E1).

Mais uma vez conforme Parse, a saúde é a qualidade de vida a partir da perspectiva da pessoa ${ }^{1}$. Deste modo, 0 enfermeiro deve considerar os desejos do paciente e valorizar suas vontades, quando estas estiverem de acordo com 0 tratamento. Também é essencial o uso de estratégias para obter a adesão do paciente. Isso facilitará o cuidado. Por exemplo, o trabalho junto à equipe multiprofissional é uma ferramenta poderosa para se prestar um cuidado de qualidade ao hipertenso, e sua relevância foi citada pelos enfermeiros entrevistados, como exposto:

A gente faz umas palestras educativas, têm a colaboração de outros profissionais de nível superior, aí tem toda a equipe multiprofissional [...] tem educador físico, tem assistente social, tem o terapeuta ocupacional, às vezes, fisioterapeuta (E4).

Ainda como estratégia para adesão do tratamento de pessoas hipertensas, sobressai o diálogo firmado entre as partes (enfermeiro e paciente) para o estabelecimento de estratégias e decisões sobre o tratamento. Contudo, é indispensável um processo de educação permanente com vistas a manter a adesão quanto às condutas de controle da $\mathrm{HAS}^{13}$.

\section{Mobilização da transcendência - o enfermeiro guia o plano de mudanças}

No terceiro princípio de Parse, aborda-se a adaptação do paciente. Nele se discorre sobre mudança de estilo de vida, conforme será melhor exemplificado a seguir.

De modo geral, a mobilização da transcendência dá-se pelo processo de ir além do significado do momento para aquilo que ainda não é. "Essa dimensão focaliza o sonhar com os possiveis e o planejar para realizar os sonhos" ${ }^{\prime 14}$.

Considerando o teorizado por Parse, mudanças no estilo de vida são fundamentais para o controle da hipertensão arterial. Cabe ao enfermeiro articular com o paciente tais mudanças, de acordo com as possibilidades deste, tornando seu estilo de vida mais condizente com seu estado de saúde. Neste processo de mudança de pensamento, o enfermeiro se depara com muitas dificuldades, mas tenta superá-las, como vê-se a seguir:

E a gente ainda tem um agravante, porque é um número considerável de fumantes, e para a gente tirar e convencer que o cigarro faz mal e tudo. Mas a gente já vê melhora, quando eles começam a seguir as orientações da gente, que eles veem um resultado, que eles se sentem melhor, aí eles começam a realmente acreditar no serviço (E7).
Segundo se propõe, a essência da enfermagem é o relacionamento entre enfermeiro e indivíduo ou familiares, e a meta da prática da enfermagem é melhorar a qualidade de vida sob a perspectiva da própria pessoa'.

Neste prisma, a enfermeira vale-se de meios que favoreçam a mudança na rotina e no estilo de vida do paciente, pois alguns não aderem ao tratamento por dificuldades de compreendê-lo. 0 discurso a seguir mostra um exemplo da utilização de métodos que facilitem o seguimento da terapêutica:

Tem que ter kits que identifiquem melhor os medicamentos, né? Que facilite porque eles, devido não saberem ler, eles têm uma grande dificuldade em diferenciar. Mas através da estratégia de você diferenciar por cores, por tamanho, para eles saberem (E1).

Outro suporte na mudança da rotina e do estilo de vida dos hipertensos é a família. Esta, como mediadora no estabelecimento de um plano terapêutico, tem fundamental importância no tratamento ao hipertenso e na sua mudança de comportamento. Na definição de Parse, a família são os outros com quem se está intimamente ligado. Esta definição ressalta a natureza inter-relacional na perspectiva de família. Segundo a fala a seguir, os enfermeiros estão cientes do significado da família no cuidado ao hipertenso:

Saber se a pessoa, na família, tem alguém responsável, também; se a família contribui [...] porque é muito importante a parte da família (E13).

Ademais, para que o plano terapêutico seja estabelecido de forma a obter adesão, precisa-se ainda considerar as condições sócio-econômico-culturais do paciente e, assim, viabilizar com este as devidas alterações. Como E1 enfatiza, 0 enfermeiro deve adequar suas orientações às condições do paciente:

Então, nesse sentido, eu já tenho um pouco de controle [...] que ele não coma exageradamente (alimentos inadequados ao hipertenso), porque, muitas vezes, é o que ele tem em casa (E1).

Entretanto, o paciente deve estar ciente de que as mudanças no estilo de vida não são apenas sugestões da equipe de saúde: elas são medidas necessárias para o controle da doença. Se não forem seguidas, pode haver sérias consequências, como o exemplificado mais uma vez por E1:

Aí, assim, a gente sempre esclarece a questão do AVC (Acidente Vascular Cerebral), do infarto, 


\section{Cuidado de enfermagem fundamentado em Parse}

porque são danos que podem vir a acontecer e pode até levar a vida deles se eles não mudarem seus hábitos.

Inegavelmente, cada indivíduo tem seu ritmo; o homem vive em ritmicidade com as constantes mudanças do universo. Isso gera diversas mutações verificadas nos paradoxos do dia a dia, de acordo com as experiências humanas. Logo, não se pode esperar reações iguais em indivíduos diferentes, pois cada um tem sua forma e seu tempo para assimilar as informações e tomar uma atitude ${ }^{11}$.

Considerar as possibilidades de transcendência do paciente diante do seu adoecimento desperta a mudança na prática assistencial; contudo, ainda se depara com inúmeras dificuldades para humanizar o atendimento e aproximá-lo do preconizado pelas teorias de enfermagem, as quais prezam por um cuidado integral. Uma dessas dificuldades é a falta de um quantitativo de recursos humanos adequado, o que acaba por tornar a demanda superior ao poder de resolubilidade da equipe.

Trabalhar na área da saúde constitui um grande desafio para os profissionais, por ser este um campo com intensa demanda de usuários e muitas limitações, tanto no campo da gerência como dos trabalhadores e da política. De um lado, estão as necessidades da população e do outro, os gestores com as questões financeiras, de recursos humanos e materiais, quase sempre aquém da demanda da população, seja em quantidade ou em qualidade ${ }^{15}$. Este fato foi citado pelos entrevistados como dificultador de uma assistência de qualidade:

O ruim é a quantidade de pessoas com hipertensão. A gente chega a atender sessenta (hipertensos por dia). Então, o nosso cuidado aqui está dentro do limite [...] e também esbarra na burocracia, né?! (E4).

Todavia, mesmo com todas as adversidades enfrentadas em virtude da burocracia de um sistema de saúde ainda falho e em processo de implantação, os profissionais atuantes tentam, na medida do possível, prestar um cuidado de qualidade. Eles acreditam na melhoria do serviço saúde como mostra o discurso:

[...] eu creio que a Estratégia Saúde da Família é uma estratégia que realmente é uma coisa positiva, mas a nossa cidade ainda tem entraves, porque, dentro da gestão, ainda está precisando de recursos humanos para poder dar cobertura na nossa área. [...]Mas eu acredito que a gente avançou. Eu sei que diante dessa realidade, o município hoje tem quatorze equipes. Ele vai poder se reorganizar melhor (E10).
É visível a esperança de melhorar o sistema de saúde e o empenho para otimizar o atendimento prestado. Diante do exposto, considera-se que a proposta dos princípios de Parse é relevante, e sua utilização pelo enfermeiro é um adjuvante, pois traria aperfeiçoamento a uma prática já instituída, mas ainda com limitações.

\section{CONCLUSÕES}

Este estudo se propôs a encontrar aproximaç̃̃es entre a prática de cuidar dos enfermeiros da ESF e a proposta por Parse em sua teoria. Considerando esta premissa, foi possível identificar similaridades teóricas, as quais muitas vezes não passaram do campo ideológico e, outras vezes, foram encontradas imaturamente na prática. Um exemplo é o cuidado humanizado, o qual está bem fundamentado subjetivamente para os enfermeiros, mas não está sendo praticado de forma condizente.

Notou-se também, no decorrer do estudo, que um grande dificultador da prática de um cuidar mais amplo é a burocracia de um sistema de saúde ainda falho, que não permite ao profissional atuar de forma condizente com sua fundamentação teórica, já que a demanda exige uma consulta rápida e, na maioria das vezes, padronizada.

Contudo, viu-se que, mesmo com estes dificultadores, os enfermeiros têm buscado incentivar o autocuidado e a participação do paciente na formulação do seu plano terapêutico. As orientações de enfermagem, citadas nos discursos, buscaram ser flexíveis e considerar a individualidade de cada paciente. Também foi possível notar que os entrevistados têm enfatizado a importância da participação da familia como facilitadora deste processo. Todos estes aspectos são condizentes com 0 protagonismo e autonomia teorizados por Parse.

Como se depreende, a Teoria de Parse aborda questões aptas a instrumentalizar o enfermeiro a trabalhar a qualidade de vida na perspectiva da própria pessoa. No entanto, apesar da sua aplicabilidade no contexto das doenças crônicas, como a HAS, pouco se encontra a seu respeito na literatura nacional.

Neste âmbito, cabe salientar que houve limitações no desenvolvimento do estudo devido à dificuldade quanto a tradução dos termos do inglês para o português, pois a teoria é escrita em um discurso de nível filosófico e em uma linguagem pouco comum na área da enfermagem. Contudo, mesmo sem um maior aprofundamento da teoria, foi possível perceber a aplicabilidade de suas ideias na prática.

Outro ponto da teoria, considerado positivo, é o fato de promover ampliação do corpo de conhecimentos do profissional enfermeiro, além de the permitir estar verdadeiramente presente com o paciente. Sendo assim, percebe-se que a aplicação da teoria na prática é possível, desde que, conhecendoa, o enfermeiro realmente assuma seus pressupostos, crenças e valores e a adote como prática cotidiana, modificando suas atitudes e modo de ser diante das experiências de vida da 


\section{pessoa cuidada.}

Ademais, o estudo desenvolvido serve como incentivo a mudanças na prática dos enfermeiros, os quais poderiam rever a questão do acolhimento como ferramenta de interação e criação de vínculo, com vista a um cuidar mais individualizado. 0 incentivo à autonomia poderia ser feito de forma mais eficiente ao trabalhar a educação em saúde e grupos de apoio aos pacientes com hipertensão, nos quais haveria momentos de trocas de experiências entre os que vivenciam o mesmo adoecimento, atuando o enfermeiro como facilitador deste processo, ao esclarecer dúvidas e incentivá-los a seguir 0 tratamento.

Estas mudanças não são fáceis, sobretudo em decorrência de entraves estruturais do sistema de saúde, mas, se implementadas, pode-se ter um retorno positivo, porquanto a demanda poderá se tornar menor tanto na porta de entrada do sistema, a atenção básica, como nos serviços especializados, já que é possível prevenir complicações de uma hipertensão mal controlada.

\section{REFERÊNCIAS}

1.Parse RR. Illuminations: the human becoming theory in practice and research. New York(EUA): Nactional League for Nursing; 1995.

2.Oliveira CJ, Moreira TMM. Caracterização do tratamento nãofarmacológico de idosos portadores de hipertensão arterial. Rev. RENE. 2010 jan/mar; 11(1): 76-85.

3.Souza SNDH, Rozzeto EG, Sodré TM. Aplicação da Teoria de Parse no relacionamento enfermeiro-indivíduo. Rev. Esc. Enferm. USP. 2000 set; 34(3): 244-51.

4. Michel GJ, Copplestone C. Applying Parse's Theory to perioperative nursing. AORN J. 1990 mar; 51(3): 787-98.

5.Tanaka J, Katsuno T, Takahashi T. Using Parse's human becoming Theory in Japan. Nurs Sci Q. 2012; 25(1): 99-102.

6.Fiorin JL. Elementos de análise do discurso. $14^{\mathrm{a}}$ ed. São Paulo: Contexto; 2008.

7.Gussi MA, Dytz JLG. Religião e espiritualidade no ensino e assistência de enfermagem. Rev. bras. enferm. 2008 maio/jun; 61 (3): 377-84.

8.Neves MJAO, Branquinho NCSS, Paranaguá TTB, Barbosa MA, Siqueira KM. Influência do trabalho noturno na qualidade de vida do enfermeiro. Rev. enferm. UERJ. $2010 \mathrm{jan} / \mathrm{mar} ; 18(1)$ : $42-7$.

9.Erdmann AL, Leite JL, Nascimento KC, Lanzoni GMM. A iniciação cientifica na formação do graduando. Esc Anna Nery. $2010 \mathrm{jan} / \mathrm{mar}$; 14(1): 26-32.
10. Barros SDOL, Queiroz IC, Melo RM. Cuidando e humanizando: entraves que dificultam essa prática. Rev. enferm. UERJ. 2010 out/ dez; 18(4): 598-603.

11. Parse RR. Hope: an international human becoming perspective. Toronto(CAN): Jones and Bartlett Publishers International Inc., National League for Nursing; 1999.

12. Parse RR. Man-living-health: a theory of nursing. New York(EUA): John Wiley \& Sons; 1981.

13. Lima HP, Santos ZMSA, Nascimento JC, Caetano JA. Adesão do usuário hipertenso ao tratamento e a interface com o saber sobre o agravo. Rev. RENE. 2010 abr/jun; 11(2): 170-178.

14. Parse RR. Nursing science: major paradigms, theories and critiques. Philadelphia(EUA):W. B. Saunders: 159-80; 1987.

15. Santos AS, Miranda SM. A enfermagem na gestão em atenção primária à saúde. São Paulo(SP): Manole; 2007.
Recebido em 20/05/2012 Reapresentado em 28/08/2012 Aprovado em 11/09/2012 